\title{
ЗА РУБЕЖОМ
}

DOI https://doi.org/10.34216/2073-1426-2020-26-4-223-229

УДК 159.923

\author{
Корнилова Татьяна Владимировна \\ Вологодский институт права и экономики \\ Федеральной службы исполнения наказаний России
}

\section{СОВРЕМЕННЫЕ ЗАРУБЕЖНЫЕ ИССЛЕДОВАНИЯ ФЕНОМЕНА ЖИЗНЕСТОЙКОСТИ (HARDINESS)}

\begin{abstract}
В статье обобщен материал зарубежсных исследований, проводимых в 2015-2020 г2. американскими, канадскими, норвежскими, украинскими, китайскими и др. учеными и посвященных изучению феномена жизнестойкости (hardiness). Раскрыты компоненты жизнестойкости и выделены основные направления в ее изучении. Выявлено, что жизнестойкость напрямую взаимосвязана со многими позитивными личностными характеристиками, способствует сохранению здоровья и повышенной работоспособности. Также автором отмечается высокая степень согласия между зарубежными исследователями по факту благоприятного воздействия жизнестойкости на личность в стрессовых и даже экстремальных условиях, в связи с чем обращается внимание на актуальность изучения и возможную психокоррекцию показателей жизнестойкости у различных категорий осужденных.

Ключевые слова: жизнестойкость личности, компоненты жизнестойкости, зарубежные исследования жизнестойкости, жизнестойкость осужденных
\end{abstract}

Информация об авторе: Корнилова Татьяна Владимировна, Вологодский институт права и экономики Федеральной службы исполнения наказаний России, старший научный сотрудник организационно-научного отдела, г. Вологда, Россия

E-mail: tanya.bystrova2012@mail.ru

Дата поступления статьи: 23.09.2020

Для цитирования: Корнилова Т.В. Современные зарубежные исследования феномена жизнестойкости (hardiness) // Вестник Костромского государственного университета. Серия: Педагогика. Психология. Социокинетика. 2020. T. 26, № 4. С. 223-229. DOI https://doi.org/10.34216/2073-1426-2020-26-4-223-229

Tat'yana V. Kornilova Vologda Institute of Law and Economics of the Federal Penitentiary Service of Russia

\section{MODERN FOREIGN STUDIES OF THE PHENOMENON OF HARDINESS}

The article summarises the material of foreign research conducted by American, Canadian, Norwegian, Ukrainian, Chinese and other scientists in 2015-2020. This foreign research is devoted to the study of the phenomenon of hardiness. The article reveals the main components of hardiness and highlights the main directions in the study of hardiness. It is determined that hardiness is directly related to many positive personal characteristics, it helps to maintain health and increase productivity. The author notes a high degree of agreement between foreign researchers on the fact of the beneficial impact of hardiness on a person in stressful and even extreme conditions, in connection with which attention is drawn to the relevance of the study and possible psychocorrection of vitality indicators in various categories of convicts.

Keywords: individual hardiness, components of hardiness, foreign studies of hardiness, hardiness convicts

Information about the authors: Tat'yana V. Kornilova, Senior Reseacher, Vologda Institute of Law and Economics of the Federal Penitentiary Service of Russia, Vologda, Russia

E-mail: tanya.bystrova2012@mail.ru

Article received: September 23, 2020

For citation: Kornilova T.V. Modern foreign studies of the phenomenon of hardiness. Vestnik of Kostroma State University. Series: Pedagogy. Psychology. Sociokinetics, 2020, vol. 26, № 4, pp. 223-229 (In Russ.). DOI https://doi.org/10.34216/20731426-2020-26-4-223-229 
B настоящее время в России активно проводятся исследования, посвященные изучению феномена жизнестойкости (hardiness). Жизнестойкость впервые описана С. Кобейса (1979) как совокупность взаимосвязанных личностных качеств или черт, которые отличают «здоровых» руководителей в условиях стресса от «нездоровых» [Kobasa]. С. Мадди охарактеризовал жизнестойкость как совокупность трех взаимосвязанных компонентов: вовлеченности, контроля и принятия риска [Maddi]. По мнению P.T. Bartone (2006), жизнестойкость - обобщенный способ функционирования личности, который включает в себя вовлеченность (убеждение, что жизнь интересна и достойна), контроль (убеждение, что можно контролировать или влиять на результаты) и принятие риска (исследующий подход к жизни). Человек «жизнестойкого стиля» имеет сильную ориентацию на будущее, или склонность смотреть в будущее, извлекая уроки из прошлого [Bartone].

P.T. Bartone, D.R. Kelly, M.D. Matthews (2013) отмечают, что жизнестойкость состоит из когнитивных, эмоциональных и поведенческих особенностей и характеризует способность человека поддерживать здоровое состояние в неспокойные времена [Bartone, Kelly, Matthews].

P. Mund (2016) предлагает дополнить компоненты жизнестойкости выделенным в 2005 году C. Мадди компонентом connection (сотрудничество - тесная связь и понимание между клиентом и психологом/психотерапевтом) и выделенным самим автором компонентом culture (культура), который особенно актуален для ее страны - Индии [Mund].

С целью подробного раскрытия понятия жизнестойкости, ее особенностей и направлений проводимых исследований, а также достигнутых в них результатов нами были проанализированы некоторые зарубежные исследования последних лет, посвященные данной проблематике.

Многие зарубежные авторы изучают и устанавливают взаимосвязь жизнестойкости с различными эмоциональными состояниями или личностными характеристиками.

Так, A. Azarian, A.A. Farokhzadian, E. Habibi (2016) с целью изучения взаимосвязи между психологической жизнестойкостью и четырьмя эмоциональными состояниями (депрессия, тревожность, гнев и позитивный аффект) провели исследование женщин в возрасте 20-35 лет, проживающих в городе Резваншахр (Rezvanshahr) в Иране. В результате исследования выявлена обратная зависимость между уровнем психологической жизнестойкости женщин и проявлениями депрессий, тревожности и гнева и прямая зависимость между уровнем психологической жизнестойкости и индексом позитивного аффекта [Azarian, Farokhzadian, Habibi].
Исследование, проведенное в Канаде C.M. Kowalski, J.A. Schermer (2019), раскрывает практическую ценность психологической жизнестойкости, а также разницу между такими понятиями, как руминация и беспокойство. Студенты заполняли опросник, оценивающий их психологическую жизнестойкость, беспокойство, руминацию, психическую вовлеченность, невротизм, тревожность, соматизацию, способность совладать со стрессом и здоровье. Была установлена обратная взаимосвязь жизнестойкости с невротизмом, руминацией, беспокойством, тревожностью и прямая взаимосвязь с психической вовлеченностью, способностью совладать со стрессом и здоровьем. При статистически регулируемом невротизме связь жизнестойкости с руминацией, здоровьем и способностью справиться со стрессом стала незначительной, в то время как связь жизнестойкости с беспокойством, психической вовлеченностью и тревожностью хоть и ослабилась, но осталась довольно сильной. Результаты говорят о том, что жизнестойкость следует скорее рассматривать как индивидуальную особенность личности, способствующую ее психологическому благополучию [Kowalski, Schermer].

Я.Г. Запека (2019) провела исследование жизнестойкости студентов украинских университетов в условиях общественно-экономического кризиса. Автором выяснено, что жизнестойкость рассматривается и как личностная черта, и как адаптационный потенциал человека в преодолении сложных жизненных ситуаций. Доказано, что лица с высоким уровнем жизнестойкости имеют более высокую степень развития смысложизненных ориентаций и более высокий показатель самоэффективности, и наоборот, у студентов с низким уровнем жизнестойкости мера выраженности смысложизненных ориентаций снижена. Студенты с высоким уровнем жизнестойкости отличаются более высоким уровнем производительности жизни, более эмоционально и с большим интересом к ней относятся, целеустремленнее, способны контролировать свою жизнь и свободно принимать решения. Во время сравнения средних значений среди мужчин и женщин выявлено статистически значимое различие по шкале «контроль», что свидетельствует о большей готовности мужчин влиять на события своей жизни [Zapeka].

B статье O.S. Halata (2020) представлен корреляционный анализ между настойчивостью в обучении и жизнестойкостью для групп студентов с высокой и низкой успеваемостью. Жизнестойкость на высоком значимом уровне связана с настойчивостью в обучении, и их соотношение может положительно влиять на учебную деятельность, помогая студенту справляться со стрессами, внешними дистракторами, а также эффективно управлять своими действиями для достижения учебной цели [Halata]. 
Многие исследования раскрывают взаимосвязь жизнестойкости со здоровьем - как с физическим, так и психическим.

Американские ученые P.T. Bartone, J.J. Valdes, A. Sandvik (2016) выявили, что многие люди ощущают, что их здоровье и психологическое благополучие ухудшается, если они находятся под воздействием стресса. Отмечается, что нейропсихологические процессы, которые характерны для жизнестойких людей, недостаточно хорошо изучены. Данное исследование посвящено изучению взаимосвязи между психологической жизнестойкостью и некоторыми показателями здоровья сердечно-сосудистой системы на основании наблюдения за 338 людьми среднего возраста, участвующими в образовательной программе, посвященной национальной безопасности. Иерархический регрессионный анализ показывает, что без дополнительного влияния, обусловленного возрастными или половыми особенностями, высокий уровень жизнестойкости определяет большое содержание в крови липопротеинов высокой плотности и меньший индекс массы тела. Низкая жизнестойкость влечет за собой повышение общего холестерина в крови в соотношении с липопротеинами высокой плотности, что является фактором риска развития сердечно-сосудистых заболеваний. Эти результаты позволяют утверждать, что психологическая жизнестойкость способствует сопротивляемости организма заболеваниям через влияние на выработку холестерина и метаболизм [Bartone, Valdes, Sandvik].

G. Mazzetti, M. Vignoli, G. Petruzziello, L. Palareti (2019) доказывают, что трансформационное лидерство как рабочий ресурс развивает жизнестойкость как личный ресурс, что в свою очередь повышает вовлеченность сотрудников в работу и в конечном итоге влияет на улучшение их здоровья, и призывают отделы по работе с персоналом проводить подготовку сотрудников, способствующую формированию лидерских качеств и, как следствие, улучшению их показателей жизнестойкости [Mazzetti et al.].

Влиянию лидерства на уровень жизнестойкости американские исследователи J.L. Judkins, B.A. Moore, T.L. Collette (2020) посвятили главу книги «Рутледжская научная энциклопедия психологии, применимой в повседневной жизни». По мнению авторов, лидеры, обладающие хорошими показателями жизнестойкости, позитивно влияют на модели поведения других членов группы, формируя у них жизнестойкость и инициируя положительные социальные изменения в группе, а впоследствии - в обществе в целом [Judkins, Moore, Collette].

Помимо исследований, показывающих влияние жизнестойких лидеров на поведение других членов группы, рассмотрим исследования, подтверж- дающие взаимосвязь жизнестойкости личности и ее поведения.

S.R. Maddi (2016) показывает, что жизнестойкость отрицательно связана с азартным поведением. Азартное поведение рассматривается как пример стратегии избегания (а не решения проблем) непрекращающихся стрессов жизни [Maddi].

Украинскими учеными (2020) приводится обзор исследований, посвященный жизнестойкости личности как фактору особой защиты, потенциально способной снизить риски суицидального поведения. В статье проанализированы публикации, авторы которых сходятся во мнении, что жизнестойкость является буфером в ситуации дистресса и частью нормализующей функции адаптивной системы человека. Отмечается, что значимость вклада некоторых параметров жизнестойкости в защиту от суицидального поведения зависит от многих индивидуальных и социокультурных факторов. Тем не менее специалисты соглашаются, что суицидальный риск связан с ослаблением резервов жизнестойкости личности и его возможно снизить в результате целенаправленного психологического вмешательства [Rothschild-Varibrus et al.].

Норвежские исследователи (2020) изучали связь между долговременным буллингом на рабочем месте и последующими изменениями в психологической жизнестойкости, а также является ли жизнестойкость фактором, влияющим на степень подверженности человека буллингу. Исследование показало, что менее жизнестойкие индивиды подвергались буллингу в большей степени с поправкой на возраст, пол и факт подверженности буллингу уже на момент начала исследования. По долгосрочной накапливаемой подверженности буллингу чаще можно было прогнозировать изменения жизнестойкости испытуемых, чем определить, насколько человек будет подвержен буллингу, исходя из показателей его жизнестойкости [Hamre et al.].

Рассмотрим другие направления изучения жизнестойкости.

Иранским исследователем Е.A. Makiabadi (2016) выявлена значимая положительная связь между продуктивным семейным взаимодействием и психологической жизнестойкостью в группах родителей с детьми-инвалидами и здоровыми детьми [Makiabadi].

Индийским автором A. Narad (2018) установлено, что домашнее окружение оказывает сильное позитивное влияние на формирование жизнестойкости школьников. При этом ученики частных школ в сравнении с учащимися государственных школ получают больше поддержки дома, вследствие чего их показатели жизнестойкости значительно выше. Показатели жизнестойкости у юношей и девушек также значительно отличаются: в частности, юноши легче принимают ситуацию риска [Narad]. 
J.R. Maramis, J. Cong (2019) выявлена обратная связь между уровнем профессионального выгорания медсестер/медбратьев больницы в Манадо (Индонезия) и их психологической жизнестойкостью. Авторы публикации рекомендуют при проведении дальнейших исследований учитывать дополнительные факторы, которые влияют на жизнестойкость и использовать более широкий спектр методов исследования [Maramis, Cong].

Крупный блок зарубежных исследований, проведенных в разных странах, посвящен изучению жизнестойкости военных. Профессиональная деятельность военнослужащих характеризуется множеством рисков и стрессоров. Участие в боевых действиях может рассматриваться как крайнее проявление экстремальных условий деятельности. Поэтому для военной службы важно отбирать и обучать жизнестойких людей, которые могут продолжать эффективно функционировать и оставаться «здоровыми» в условиях стресса.

Рассмотрим некоторые исследования, посвященные изучению жизнестойкости военных.

Норвежскими исследователями A.G. Thomassen, S.W. Hystad, B.H. Johnsen, G.E. Johnsen, J.C. Laberg, J. Eid (2015) отмечается, что, хотя многие исследования показывают связь жизнестойкости и сплоченности с психическим здоровьем в военном контексте, большинство из них не учитывают исходные симптомы психического здоровья, что является ошибкой. Данное исследование изучает совместный эффект жизнестойкости и сплоченности в перспективной модели, с учетом исходного уровня развития симптомов психического здоровья среди норвежских военных, осуществляющих миротворческую операцию в Косово. Результаты исследования показали, что и жизнестойкость, и сплоченность способствовали улучшению сопротивляемости стрессу. Для испытуемых с высоким уровнем жизнестойкости уровень сплоченности не влиял на увеличение жалоб, касающихся психического здоровья. С другой стороны, испытуемые с низкими показателями жизнестойкости меньше жаловались на проблемы с психическим здоровьем, если показатели сплоченности были высокими [Thomassen et al.].

I.C. Giurcă, A. Cătană, R. Sassu, M.D. Bucuță (2017) отмечают, что существует множество исследований, касающихся влияния нахождения в зоне военных действий (основной фактор стресса) на здоровье военных. Немногие исследования посвящены защитным факторам, которые способны предотвратить ряд проблем, возникающих у ветеранов после нахождения в зоне военных действий. Авторами изучена взаимосвязь между личностными характеристиками военнослужащих (жизнестойкость и когерентность), стратегиями копинга и показателями психического здоровья (уровень восприятия стресса и тревожности) в си- туации ожидания стрессовой ситуации. Предполагалось определить, будут ли данные показатели иметь какой-то эффект на повышение уровня психологической устойчивости военнослужащих, отправляемых в Афганистан. Характеристики испытуемых были оценены до их участия в международных военных операциях. Были предложены две гипотезы: 1) высокий уровень когерентности и жизнестойкости поможет более эффективно справляться с главными факторами стресса в ситуации ожидания стресса; 2) активный копинг с фокусом на фактор напряжения будет связан с более низким уровнем эмоционального дистресca [Giurcă et al.].

S.R. Maddi, M.D. Matthews, D.R. Kelly, B. Villarreal, K.K. Gundersen, S.C.M. Savino (2017) изучали влияние жизнестойкости и силы воли на успеваемость и сохранение контингента кадетов академии Вест Пойнт. Исследование является продолжением более раннего 4-летнего, проводимого с 2012 по 2016 гг. Результаты показывают, что жизнестойкость в бо́льшей степени определяет успеваемость и сохранение контингента, чем сила воли [Maddi et al.].

Так как военным требуется сопротивляемость стрессовым ситуациям, превосходная физическая форма, S. Lo Bue, S. Kintaert, J. Taverniers, J. Mylle, R. Delahaij, M. Euwema (2018) исследовали жизнестойкость и настойчивость в поведении во время тренировок. Кроме того, военные исследователи редко обращались к изучению влияния жизнестойкости на физическую работоспособность. В данном исследовании участвовали 233 курсанта, которые участвовали в базовом курсе тренировок длиной 22 недели. В начале курса измерялись показатели жизнестойкости. Два месяца спустя выявили, кто остался, а кто «вылетел» с курса. Оставшиеся курсанты изучали приемы самозащиты, и тренеры оценивали их уровень подготовки. Анализ показал, что показатели жизнестойкости во многом помогают спрогнозировать настойчивость в поведении: курсанты, которые продолжили заниматься через 2 месяца, демонстрировали значительно более высокие показатели по шкале жизнестойкости, чем те, кто бросили заниматься. Результаты подтверждают, что жизнестойкость имеет слабый прямой эффект на настойчивость курсантов. Во время занятий по самозащите жизнестойкость также положительно влияла на физическую работоспособность. В статье рассматривается возможная связь жизнестойкости с другими параметрами, влияющими на настойчивость военных, например здоровье, социальную поддержку [Lo Bue et al.].

Психологическая жизнестойкость ассоциируется с низким уровнем развития симптомов посттравматического стресса у военных, но механизм ее действия остается до конца не ясным. Å.G. Thomassen , S.W. Hystad, B.H. Johnsen, 
G.E. Johnsen, P.T. Bartone (2018) используют метод перспективного моделирования для изучения того, оказывает ли жизнестойкость косвенное влияние на симптомы посттравматического стресса через копинг-стратегию избегание. В исследовании принимали участие 163 норвежских военных, участвующих в международных операциях в период с 2009 по 2010 г. Был использован метод регрессивного анализа, при этом основные симптомы посттравматического стресса, интенсивность боевого опыта и лишение возможности удовлетворить свои насущные потребности были использованы как контрольные переменные. Результаты показали, что эффект жизнестойкости на развитие симптомов посттравматического стресса проявлялся через сокращение использования копингстратегии избегание. Было сделано заключение, что склонность к использованию данной стратегии является фактором уязвимости к развитию симптомов посттравматического стресса, в то время как жизнестойкость, наоборот, является фактором сопротивляемости [Thomassen et al.].

Китайские исследователи (2019) предположили посредническую роль мотивации достижения/ избегания неудач между показателями жизнестойкости и проявлениями симптомов депрессии. В исследовании участвовали военнослужащие вооруженных сил и кадеты. Авторы пришли к выводу, что у испытуемых с низкими показателями жизнестойкости и поведенческой активации и с высоким уровнем поведенческого торможения были более серьезные симптомы депрессии [Wang et al.].

M. Nordmo, O.K. Olsen, J. Hetland, R. Espevik, A.B. Bakker, S. Pallesen (2020) рассматривают жизнестойкость как преимущество в стрессовых условиях, соотносят ее с улучшением военных показателей. Последние данные свидетельствуют о том, что жизнестойкость может также быть связана с сопротивляемостью в отношении нарушений сна. Целью данного исследования является изучение сдерживающей роли жизнестойкости в соотношении качества сна и работоспособности у выборки курсантов военно-морского флота в условиях напряженного учебно-тренировочного процесса. Курсанты сначала заполнили общую анкету, а затем ежедневный дневник, оценивая качество сна во время 30-дневной учебной миссии через Атлантический океан. Ежедневная работоспособность оценивалась с помощью рейтингов коллег. Результаты многоуровневого анализа показали положительное влияние жизнестойкости на производительность труда и качество сна. Курсанты с высоким уровнем жизнестойкости менее страдали от плохого качества сна, в том числе после учета нейротизма. Полученные результаты свидетельствуют о том, что жизнестойкость смягчает влияние плохого качества сна на производительность труда [Nordmo et al.].
Военные в большей степени подвержены риску возникновения алкоголизма, чем гражданское население, а командировки в зону военных действий и интенсивность боевого опыта еще больше усиливают этот риск. J.A. Kulak, D.L. Homish, R. Hoopsick, J. Fillo, P.T. Bartone, G.G. Homish (2020) провели исследование с целью определения факторов сопротивляемости, сдерживающих негативный эффект военного опыта и выступающих в качестве превентивных мер злоупотреблению алкоголем. Авторами выявлено, что у мужчин с высокими показателями жизнестойкости прогнозируется более низкий риск возможного злоупотребления алкоголем. Также изучалось влияние каждого из компонентов жизнестойкости на формирование алкоголизма. Отмечается, что оценка жизнестойкости может быть добавлена к ряду инструментов, которые сейчас используются для выявления склонности к алкоголизму у населения, а работа психологов по формированию и усилению показателей жизнестойкости может предотвратить проблемы, связанные со злоупотреблением алкоголем, в том числе и у военных мужского пола [Kulak et al.].

Существуют публикации, в которых обсуждаются вопросы развития жизнестойкости.

В главе «Тренировка жизнестойкости в условиях сопротивляемости стрессу» из книги «Военная психология: Понятия, тенденции, варианты вмешательства» (2016) описаны программы обучения жизнестойкости, которые варьируются по сложности от довольно простых самостоятельных учебных модулей до более сложных подходов, включающих дополнительные факторы, связанные со здоровьем. В отличие от прямого обучения рассматривается и другой подход к повышению жизнестойкости - использование преимущества мощного влияния лидеров на группы. Лидеры с высокой жизнестойкостью могут оказывать положительное влияние на реагирование подчиненными на стресс [Bartone, Eid, Hystad].

Имеются исследования, отрицающие тренировку жизнестойкости.

Вопросу возможной тренировки жизнестойкости посвящено 3-летнее лонгитюдное исследование S.W. Hystad, O.K. Olsen, R. Espevik, R. Säfvenbom (2015) в контексте 3-летней программы подготовки военной академии. Кадеты из трех разных военных академий Норвегии заполняли опросник, касающийся жизнестойкости, во время первой недели подготовки и в конце каждого года обучения. Был использован метод иерархического линейного моделирования, и при этом не было обнаружено какого-то значительного влияния эффекта времени на показатели жизнестойкости [Hystad et al.].

В связи с тем, что нас непосредственно интересуют вопросы изучения жизнестойкости осужденных, то при анализе зарубежных исследований в особой 
степени обращалось внимание на исследования, проводимые в и данном направлении. К сожалению исследований, непосредственно изучавших жизнестойкость различных категорий осужденных, не выявлено. Стоит отметить, что в России исследования жизнестойкости осужденных также начали проводиться сравнительно недавно.

По нашему мнению, работа в указанной области и разработка программ коррекции и формирования жизнестойкости осужденных может способствовать снижению действия разнообразных стрессфакторов, характерных для пенитенциарной среды (ограниченное пространство, разрыв социально полезных связей, жесткая регламентация жизнедеятельности, публичность и другие), на личность. Ведь, как известно, пенитенциарный стресс может негативно влиять не только на здоровье человека, отбывающего наказание, но и способствовать различным деструктивным проявлениям (конфликты, суициды, противоправные действия и др.).

Также зачастую осужденным некуда идти после освобождения, и они совершают новые преступления, чтобы попасть туда, где их кормят, одевают и др., то есть выбирают легкие пути, а не стремятся преодолевать трудности, характерные для жизни на свободе. При этом большинство преступлений совершаются в состоянии алкогольного опьянения, следовательно, как было описано ранее, усиление показателей жизнестойкости может способствовать предотвращению проблем, связанных со злоупотреблением алкоголем.

Обобщая вышеизложенное и исходя из анализа зарубежных исследований, можно сделать вывод о том, что жизнестойкость - это интегральная способность личности, формирующаяся в раннем возрасте и достаточно стабильная с течением времени, хотя и поддается изменениям и развитию при определенных условиях. Начиная с основополагающей статьи С. Кобейса (1979), к настоящему времени проведено большое количество исследований, показывающих, что жизнестойкость способствует психологическому благополучию и прямо взаимосвязана со многими позитивными личностными характеристиками (целеустремленность, настойчивость, самоэффективность, уверенность в себе и др.), защищает от неблагоприятного воздействия стресса на психическое и физическое здоровье и работоспособность.

\section{Список литературы}

Azarian A., Farokhzadian A.A., Habibi E. Relationship between psychological Hardiness and Emotional Control Index: A Communicative Approach. International Journal of Medical Research and Health Sciences, 2016, 5, 5 (S), pp. 216-221.

Bartone P.T. Resilience under military operational stress: Can leaders influence hardiness? Military Psychology, 2006, vol. 18, pp. 131-148.
Bartone P.T., Eid J., Hystad S.W. Training hardiness for stress resilience. In book: Maheshwari N., Kumar V.V. (Eds.) Military psychology: Concepts, trends and interventions. New Delhi, 2016, pp. 231-248.

Bartone P.T., Kelly D.R., Matthews M.D. Psychological hardiness predicts adaptability in military leaders: A prospective study. International Journal of Selection and Assessment, 2013, vol. 21, № 2, pp. 200-210.

Bartone P.T., Valdes J.J., Sandvik A. Psychological hardiness predicts cardiovascular health. Psychology. Health \& Medicine, 2016, vol. 21, № 6, pp. 74-749.

Giurcă I.C., Cătană A., Sassu R. [et al.] The coping, the hardiness, and the sense of coherence as maintaining factors for military personnel's mental health. TPM: Testing, Psychometrics, Methodology in Applied Psychology, 2017, vol. 24, № 3, pp. 349-361.

Hamre K.V., Einarsen S.V., Hoprekstad Ø.L. [et al.] Accumulated Long-Term Exposure to Workplace Bullying Impairs Psychological Hardiness: A FiveYear Longitudinal Study among Nurses. International Journal of Environmental Research and Public Health, 2020, vol. 17, № 7, 2587.

Halata O.S. Educational persistence and hardiness of university students. The European Journal of Education and Applied Psychology, 2020, № 1, pp. 35-39.

Hystad S.W., Olsen O.K., Espevik R. [et al.] On the stability of psychological hardiness: a three-year longitudinal study. Military Psychology, 2015, vol. 27, № 3, pp. 155-168.

Judkins J.L., Moore B.A., Collette T.L. Psychological Hardiness. In book: The Routledge Research Encyclopedia of Psychology Applied to Everyday Life. Publisher: Abingdon, Oxon: Routledge, 2020, march. URL: https://www.researchgate.net/ publication/339882546_Psychological_Hardiness.

Kobasa S.C. Stressful life events, personality, and health - Inquiry into hardiness. Journal of Personality and Social Psychology, 1979, vol. 37, № 1, pp. 1-11.

Kowalski C.M., Schermer J.A. Hardiness, Perseverative Cognition, Anxiety, and Health-Related Outcomes: A Case for and Against Psychological Hardiness. Psychological Reports, 2019, vol. 122, № 6, pp. 2096-2118.

Kulak J.A., Homish D.L., Hoopsick R. [et al.] Hardiness protects against problematic alcohol use in male, but not female, soldiers. Psychological Services, 2020, vol. 23, № 1. URL: https://psycnet.apa.org/ record/2020-04363-001.

Lo Bue S., Kintaert S., Taverniers J. [et al.] Hardiness differentiates military trainees on behavioural persistence and physical performance. International Journal of Sport and Exercise Psychology, 2018, vol. 16, № 4, pp. 354-364.

Maddi S.R. Hardiness: An operationalization of existential courage. Journal of Humanistic Psychology, 2004, vol. 44, № 3, pp. 279-298. 
Maddi S.R. Hardiness Is Negatively Related to Gambling. Open Access Library Journal, 2016, vol. 3, № 8. URL: https://www.researchgate.net/ publication/307084786_Hardiness_Is_Negatively_ Related_to_Gambling.

Maddi S.R., Matthews M.D., Kelly D.R. [et al.] The Continuing Role of Hardiness and Grit on Performance and Retention in West Point Cadets. Military Psychology, 2017, vol. 29, № 5, pp. 355-358.

Makiabadi E.A. The study of relationship between family performance and psychological hardiness in parents with disabled Kids and normal kids. International journal of humanities and cultural studies, 2016, Special Issue, pp. 1747-1753.

Maramis J.R., Cong J. Relationship of hardiness personality with nurse burnout. Abstract Proceedings International Scholars Conference, 2019, vol. 7, № 1, pp. 434-446.

Mazzetti G., Vignoli M., Petruzziello G. [et al.] The Hardier You Are, the Healthier You Become. May Hardiness and Engagement Explain the Relationship Between Leadership and Employees' Health? Frontiers in Psychology, 2019, vol. 9, 2784.

Mund P. Kobasa Concept of Hardiness (A Study with Reference to the 3Cs). International Research Journal of Engineering, IT \& Scientific Research, 2016, vol. 2, № 1, pp. 34-40.

Narad A. Psychological hardiness among senior secondary school students: influence of home environment. Man in India, 2018, vol. 97, № 23, pp. 441-453.

Nordmo M., Olsen O.K., Hetland J. [et al.] It's been a hard day's night: A diary study on hardiness and reduced sleep quality among naval sailors. Personality and Individual Differences, 2020, vol. 153. URL: https://elib.pstu.ru/vufind/EdsRecord/a9h,139584995.

Rothschild-Varibrus V., Fritzsche L., Korzhenevskyi $S$. [et al.] Hardiness in aspects of suicidal prevention (Literature review). Ukrains'kyi Visnyk Psykhonevrolohii, 2020, vol. 28, № 1 (102), pp. 84-88.

Thomassen A.G., Hystad S.W., Johnsen B.H. [et al.] The effect of hardiness on PTSD symptoms: A prospective mediational approach. Military Psychology, 2018, vol. 30, № 7, pp. 142-151.

Thomassen A.G., Hystad S.W., Johnsen B.H. [et al.] The combined influence of hardiness and cohesion on mental health in a military peacekeeping mission: A prospective study. Scandinavian Journal of Psychology, 2015, vol. 56, № 5, pp. 560-566.

Wang X., Wong J.Y.-H., Zhai L. [et al.] To Approach or to Avoid? Motivation Differentially Mediates the Effect of Hardiness on Depressive Symptoms in Chinese Military Personnel. BioMed Research International, 2019, Special Issue, may. URL: https:// www.hindawi.com/journals/bmri/2019/7589275/.

Zapeka $Y$. Empirical research of students' hardiness. Scientic Bulletin of Kherson State University. Series Psychological Sciences, 2019, № 4, pp. 87-93. 